\title{
Soil inoculation of Trichoderma asperellum M45a regulates rhizosphere microbes and triggers watermelon resistance to Fusarium wilt
}

\author{
Yi Zhang ${ }^{1,2}$, Cheng Tian², Jiling Xiao ${ }^{2}$, Lin Wei ${ }^{3}$, Yun Tian ${ }^{{ }^{*}}$ and Zhihuai Liang ${ }^{2^{*}}$
}

\begin{abstract}
Fusarium wilt (FW) caused by Fusarium oxysporum f. sp. niveum (FON) is a soil-borne disease that seriously limits watermelon production. In the present study, Trichoderma asperellum (T. asperellum) M45a was shown to be an effective biocontrol agent against FW. In a pot experiment, the application of $10^{5} \mathrm{cfu} / \mathrm{g}$ of T. asperellum M45a granules had an improved control effect on FW during the blooming period (up to 67.44\%) in soils subjected to five years of continuous cropping with watermelon, while the average length of watermelon vines was also significantly improved $(P<0.05)$. Additionally, the acid phosphatase $(A C P)$, cellulase $(C L)$, catalase $(C A T)$, and sucrase $(S C)$ activities in the M45a-inoculation group were significantly higher than those in the control (CK) group, and transformation of the soil nutrients (total N, NO3-N, and available P) was significantly increased. Moreover, T. asperellum M45a inoculation reduced fungal diversity, increased bacterial diversity and especially enhanced the relative abundance of plant growth-promoting rhizobacteria (PGPR), such as Trichoderma, Sphingomonas, Pseudomonas, Actinomadura, and Rhodanobacter. Through functional prediction, the relative abundance of ectomycorrhiza, endophytes, animal pathotrophs, and saprotrophs in the fungal community was determined to be significantly lower than that observed in the M45a-treated soil. Correlation analysis revealed that Sphingomonas, Pseudomonas, and Trichoderma had the most differences in terms of microorganism abundance, and these differences were positively correlated with ACP, $\mathrm{CL}, \mathrm{CAT}$, and SC. These findings provide guidance for the use of fungicides to achieve microecological control of FW in continuously cropped watermelon plots.
\end{abstract}

Keywords: Trichoderma asperellum M45a, Fusarium wilt, Rhizosphere microorganism, Watermelon

*Correspondence: tianyun79616@163.com; liangzhihuainky@163.com ${ }^{1}$ College of Bioscience and Biotechnology, Hunan Agricultural University, Changsha, Hunan, China

${ }^{2}$ Institute of Agricultural Biotechnology Research, Hunan Academy of Agricultural Sciences, Changsha, Hunan, China

Full list of author information is available at the end of the article

\section{Introduction}

Continuous cropping can result in stunted crop growth, disease aggravation, and decreased quality, and it can create a bottleneck that restricts the sustainable development of agriculture (Wu et al. 2009a, b). However, vegetable planting in facilities with single and continuous cropping is widespread in China due to the restriction of production and cultivation conditions and economic interests (Gao et al. 2019). Soil sterilization is the main measure to overcome the obstacles associated with continuous cropping production. Although this approach can alleviate obstacles, it causes substantial harm to the 
environment in the long run. Therefore, environmentally friendly methods to alleviate continuous cropping obstacles by regulating soil microbial communities are being explored (Umadevi et al. 2018).

Soil microorganisms and soil enzymes are important components of soil ecosystems and important indexes to evaluate soil ecological quality and soil fertility ( $\mathrm{Li}$ et al. 2018). Moreover, continuous cropping often leads to changes in nutrient contents, soil enzyme activity, and other physical and chemical properties, as well as changes in the soil microbial environment, which restrict the absorption of nutrients in soil and can cause soilborne diseases (An et al. 2011). The plant rhizosphere, which is the region of soil that adheres to plant roots, is the site of complex ecological and biological processes and is affected by root exudates (Fang et al. 2013; Philippot et al. 2013). Microorganisms in the plant rhizosphere play a key role in maintaining ecosystems, and the abundance and diversity of microbial communities are sensitive to fertilization, irrigation, and plant health (Mazzola, 2004; Raaijmakers et al. 2009; Zhao et al. 2018; Zhou et al. 2017). For watermelon, changes in the microbial rhizosphere community may affect the plant's resistance to Fusarium oxysporum f. sp. niveum (FON) (GarcíaRuiz et al. 2008). In addition, soil enzyme activity plays an important role in nutrient cycling and reflects the total soil biological activity, which may be associated with plant diseases. Additionally, soil microorganisms are the promoters and participants of soil biochemical reactions and have a direct correlation with soil enzyme activities (Wang et al. 2018).

Watermelon (Citrullus lanatus) is one of the most popular summer fruit crops worldwide (Guo et al. 2013). However, watermelon growth and yields have been significantly reduced by several soil-borne diseases, such as Fusarium wilt (FW) (Zhang et al. 2005) and blight disease (Zhang et al. 2016). FW, which is one of the most harmful diseases, is caused by FON and leads to decreased yields (An et al. 2011). This fungal pathogen population can reside in the soil for a long time and be rapidly affect plant roots, which leads to necrosis and induces wilting during the later stages of infection, thereby reducing yields and limiting economic productivity (Liu et al. 2019).

Trichoderma species are opportunistic, act as biocontrol agents, have the ability to induce plant resistance, and promote plant growth; thus, some Trichoderma species has been used as effective biofertilizers and biocontrol agents for plants grown in greenhouses and fields (Hermosa et al. 2012; Pandey et al. 2016). For example, Yuan et al. (2018) demonstrated that five Trichoderma strains substantially facilitated the growth and improved the nutritional quality of orchard grass. Yang et al. (2011) also showed that Trichoderma harzianum (SQR-T307) is an efficient biological control agent against Fusarium oxysporum. He et al. (2019) found that Trichoderma asperellum GDFS1009 granules can promote growth and resistance to Fusarium graminearum in maize. In recent years, most studies on the microbial community of the soil rhizosphere have mainly focused on bacterial communities, and limited information is available on fungal communities (Yu et al. 2013; Zhao et al. 2014; Shen et al. 2015a, b; Shen et al. 2015a, b). However, a few studies have been conducted on the effect of Trichoderma asperellum on the growth of continuously cropped watermelon, particularly the microecological regulation mechanism in the rhizosphere during the pathogenesis of FW. The hypothesis is that the application of Trichoderma asperellum strain M45a (T. asperellum M45a) can change the compositions of the bacterial and fungal communities in the rhizosphere soil of continuously cropped watermelon. In this study, we used high-throughput sequencing to compare the rhizosphere microbial communities before and after treatment with $T$. asperellum M45a and explored the underlying mechanisms on plant growth promotion and disease (FW) suppression.

\section{Materials and methods}

Trichoderma strains and plant material

Trichoderma asperellum M45a (CCTCC NO: M2019513, China Center for Type Culture Collection) provided by the Hunan Agricultural Biotechnology Research Institute, Changsha, China, was used throughout our study. T. asperellum M45a was cultured in potato dextrose agar (PDA) broth at $28^{\circ} \mathrm{C}$. A T. asperellum M45a conidia suspension was prepared according to Zhang et al. (2013b), and the determined concentration was $7.5 \times 10^{6}$ colonyforming units $(\mathrm{cfu}) / \mathrm{ml}$. The watermelon cultivar 'Zaojia $8424^{\prime}$, which is susceptible to FON, was used to investigate FW disease incidence (Faheem et al. 2015) and the length of watermelon vines.

\section{Greenhouse experimental design and soil sample collection}

In the greenhouse experiment, potting soil was collected from a field at the Hunan Academy of Agricultural Sciences in Hunan, China (lat. $28^{\circ} 28^{\prime} 55^{\prime \prime} \mathrm{N}$ and long. $113^{\circ}$ $20^{\prime} 58^{\prime \prime} \mathrm{E}$ ), which had been subjected to five years of continuous cropping with watermelon. The clay soil contained $2.7 \%$ organic matter, $1818.68 \mathrm{mg} / \mathrm{kg}$ of total $\mathrm{N}$, $438.13 \mathrm{mg} / \mathrm{kg}$ of available $\mathrm{K}, 73.26 \mathrm{mg} / \mathrm{kg}$ of available $\mathrm{P}$, and $\mathrm{pH}=4.6$. The soil enzyme activity levels were as follows: $0.7 \mathrm{u} / \mathrm{g}$ ACP, $9.44 \mathrm{u} \cdot \mathrm{g}^{-1} \mathrm{CL}, 26.30 \mathrm{u} / \mathrm{g}$ CAT, 6.545 $\mathrm{u} / \mathrm{g} \mathrm{SC}$, and $683.18 \mathrm{u} / \mathrm{g}$ UE. The concentration of FON in the soil was $5 \times 10^{3} \mathrm{cfu} / \mathrm{g}$, and the content of Trichoderma spp. was $1.77 \times 10^{4} \mathrm{cfu} / \mathrm{g}$. Two treatments were 
performed in the greenhouse experiment in May 2018: a Trichoderma treatment $(200 \mathrm{ml}$ of the Trichoderma asperellum M45a conidial suspension $\left(7.5 \times 10^{6} \mathrm{cfu} / \mathrm{ml}\right)$ was added to $15 \mathrm{~kg}$ of soil, and this mixture was sprayed and mixed to achieve a concentration of $1.0 \times 10^{5} \mathrm{cfu} / \mathrm{g}$ in the test soil) and Control (add $200 \mathrm{ml}$ of sterile water to $15 \mathrm{~kg}$ of soil). Each treatment included five plastic pots and 30 seeds per pot, and all the plastic pots were laid out randomly. All watermelon plants were grown in a greenhouse with temperatures ranging from 28 to $35^{\circ} \mathrm{C}$, with natural light during the day, and from 22 to $25^{\circ} \mathrm{C}$ at night.

In addition, soil samples were collected from two treatments in June and July of 2018. Each rhizosphere soil sample was collected from five watermelon plants during the germination period (S1), the seedling period (S2), the smoke trailing period (S3), and the blooming period (S4). All the soil samples were sieved (2-mm mesh) and divided into two subsamples: one subsample was stored at $4{ }^{\circ} \mathrm{C}$ for soil enzyme activity and property analyses, and the other subsample was stored at $-60{ }^{\circ} \mathrm{C}$ for DNA extraction.

\section{Soil enzyme activities and properties}

For each rhizosphere soil sample, the activities of the extracted soil enzymes were determined fluorometrically using methylumbelliferone (MUB)-linked model substrates with a TECAN Infinite M200 spectrophotometer (G10S UV-Vis, Thermo Fisher, USA), including soil acid phosphatase activities, soil urease (Emami et al. 2013), soil cellulase (Kizilkaya et al. 2012), soil sucrase, and soil catalase activities (Allison and Jastrow, 2006), which were detected at the following wavelengths: $450 \mathrm{~nm}$ for S-CAT and $365 \mathrm{~nm}$ for the other enzymes. Then, the contents of soil organic matter (OM) (method GB9834-1988), soil total nitrogen (TN), available nitrogen (AN) (modified Kjeidahl method, HJ/T 707-2014), soil available kalium (AK) (flame atomic absorption spectrophotometry method, GB 9836-1998), and soil available phosphorus (AP) (sodium hydrogen carbonate solution-Mo-Sb anti spectrophotometric method, HJ/T 704-2014) were measured by the Institute of Soil Science, Chinese Academy of Sciences (Nanjing, China).

\section{Quantitative PCR analysis of Trichoderma spp. and FON}

The abundances of Trichoderma spp. and F. oxysporum f. sp. niveum (FON) in the rhizosphere soil and root tissue of the watermelon plants were estimated using real-time PCR assays with an IQ5 Real-time PCR system (Bio-Rad Lab, LA, United States). The Trichoderma species were quantified using quantitative PCR with DG/DT primers (5'-CTGGCATCGATGAAGAAC G-3'/5'-ATGCGAGTGTGCAAACTACTG-3') (Wei et al. 2013). The FON species was preamplified by PCR for 18 cycles by Fonq-F/Fonq-R(5'-GTTGCTTACGGT TCTAACTGTGC-3' $/ 5^{\prime}$-GGTACTTGGAAGGAATTG TGGG-3'), and then fluorescence quantitative PCR was performed using $1 \mu \mathrm{l}$ of PCR product as a template in our laboratory (Xiao et al. 2018). The initial copy number of the target gene was calculated by comparing the threshold cycle $(\mathrm{Ct})$ values of each sample with the calibration curve. The Trichoderma standard equation was set up for is $y=-0.3328 x+12.551, R^{2}=0.9865$ ( $y$ : the threshold cycle; $x$ : the log of the spore concentration), and the calibration curve for FON was fixed according to the methods suggested by Xiao et al. (2018). Sterile water was used as a negative control. All amplifications were conducted three times.

\section{Rhizosphere soil DNA extraction and sequencing}

DNA from each rhizosphere soil sample was extracted from $100 \mathrm{mg}$ of soil using a MoBio kit (MO BIO Laboratories, Inc., USA) according to the manufacturer's instructions. The quality of the DNA samples was measured using a NanoDrop spectrophotometer (2000/2000C, Thermo Scientific, USA), and $2 \mu \mathrm{L}$ of each sample was subjected to electrophoresis on a $0.8 \%$ agarose gel using a $1 \times$ TAE buffer. Three replicates for each treatment were obtained in our experiment.

For the bacterial community analysis, the bacterial $16 \mathrm{~S}$ rRNA gene was amplified using the following primers: 338F (5'-ACTCCTACGGGAGGCAGCA- $\left.3^{\prime}\right)$ and 806R (5'-GGACTAC HVGGGTWTCTAAT-3') (Zhao et al. 2014). For the fungal community analysis, the internal transcribed spacer (ITS) regions were amplified using the following primers: ITS 5F (5'-GGA AGTAAAAGT CGTAACAAGG-3') and ITS 1R (5'-GCTGCGTTC TTCATCGATG C-3') (Lopez-Mondejar et al. 2010). The DNA library was prepared with the TruSeq Nano DNA LT Library Prep Kit for Illumina. Sequencing of the paired-end library was performed using the Illumina MiSeq PE250 sequencing platform. The raw sequence data have been submitted to the NCBI sequence Read Archive (SRA) under accession numbers SRP265681 and SRP265697.

\section{Data analysis and statistical analyses}

Raw bacterial and fungal sequences were assigned to each sample based on the corresponding unique barcodes. The sequences were clustered into operational taxonomic units (OTUs) at $97 \%$ sequence similarity by utilizing UCLUST (Edgar 2010) after quality control and elimination of short reads, chimaeras, ambiguous sequences, and low-quality sequences using QIIME (Caporaso et al. 2010). The OTUs were classified using the UNITE and Greengenes databases for fungi and bacteria, respectively 
(Desantis et al. 2006; Urmas et al. 2013). To analyse the differences in the bacterial and fungal community structures among the different treatments, principal coordinate analysis (PCoA) (Jiang et al. 2013) and redundancy analysis (RDA) (Jongman et al. 1995) were applied. Differences in the parameters among treatments were compared by performing one-way analysis of variance (ANOVA) at the end of each bioassay followed by Duncan's multiple range tests in IBM SPSS Statistics 25.0 $(P<0.05)$. A value of $P<0.05$ was regarded as significant.

\section{Results}

\section{Effect of T. asperellum M45a on watermelon health properties and FON content}

The effect of T. asperellum M45a on watermelon health parameters was assessed based on the disease incidence (DI) of FW and the length of the watermelon vines. FW disease occurs in the seedling stage and then erupts rapidly until it becomes stable in the flowering stage. Compared to the CK treatment, the biocontrol effects of T. asperellum M45a on watermelon FW disease were $89.65 \%, 72.62 \%$, and $66.72 \%$ during the seedling period (S2), the smoke trailing period (S3), and the blooming period (S4), respectively, and these results were significantly different from those of the CK group during the same periods $(P<0.01)$ (Fig. 1a). Additionally, the vine lengths of the watermelons inoculated with strain M45a also increased significantly by $29.44 \%, 26.43 \%$, and $49.15 \%$ in the S2, S3, and S4 periods, respectively (Fig. 1b).

To understand the dynamic colonization relationship between Trichoderma spp. and FON in the rhizosphere soil, the qPCR technique was applied. We found that the number of FON in the CK treatment rapidly increased to $9543.66 \mathrm{cfu} / \mathrm{g}$ in the germination period (S1), which was significantly higher than of the T. asperellum M45a treatment. Except for the smoke trailing period (S2), the number of FON in the control rhizosphere soil was significantly higher than that in the M45a treatment (Fig. 1a). In addition, the contents of Trichoderma spp. in the rhizosphere soil of the M45a treatment were 22.07, 16.64, 12.35, and 23.05 times higher than those of the CK treatment during the same stage, respectively, and remained at $3.00 \times 10^{6}$ $5.64 \times 10^{6} \mathrm{cfu} / \mathrm{g}$ for the onset of FW (Fig. 1b).

\section{Effect of T. asperellum M45a on soil enzyme activities and properties in rhizosphere soil}

In the study, the enzyme activities of $\mathrm{CL}, \mathrm{ACP}, \mathrm{CAT}$, and $\mathrm{SC}$ in the rhizosphere soil were increased following treatment with M45a, except for the activities of $\mathrm{SC}$ in the seedling period (S2) (Fig. 2). For example, the maximum increases in the activities of SC (224.15\%) and ACP (95.80\%) were obtained in the smoke trailing period (S3). Additionally, the activities of UE in the control group decreased gradually with the occurrence of watermelon FW. In contrast, the M45a treatment could effectively enhance the UE enzyme activity, and the highest activity (501.478 U/g) was observed in the S4 period. In addition, no significant difference was observed in the $\mathrm{OM}$ and available $\mathrm{K}$, while the TN and available nutrients (NO3-N, and $\mathrm{P}$ ) varied significantly in the different treatments (Table 1). Compared with the CK treatment, the M45a treatments significantly increased the contents of $\mathrm{TN}, \mathrm{NO} 3-\mathrm{N}$, and $\mathrm{AP}$ and decreased the AK content.
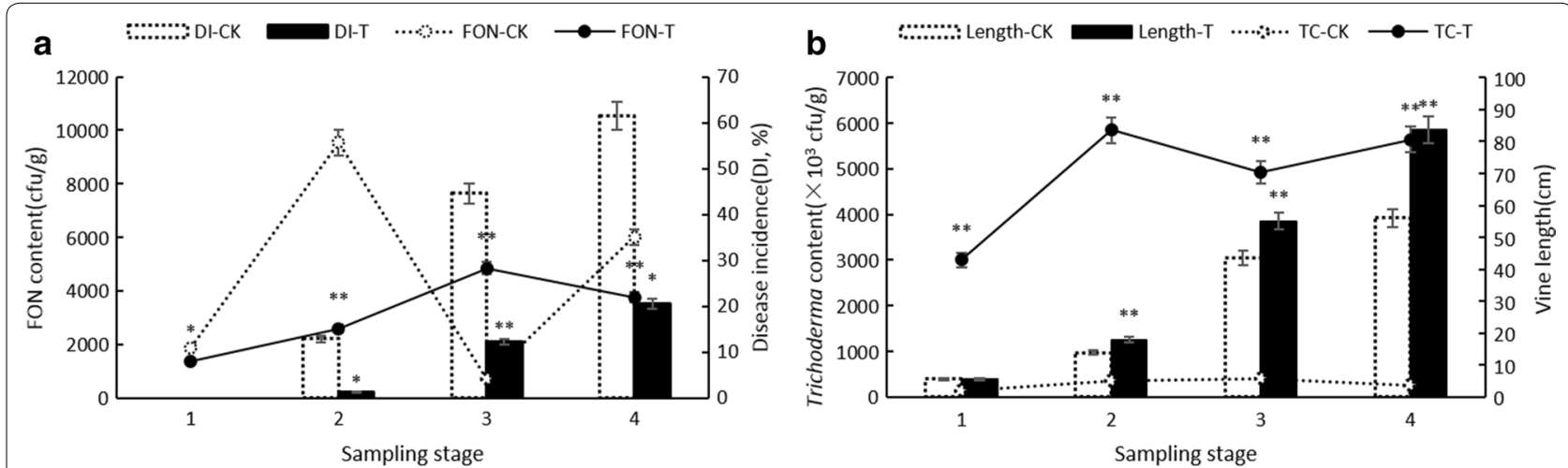

Fig. 1 Effect of inoculating M45a on watermelon health properties and FON content. The inoculation of T. asperellum M45a in continuous cropping soil (T). The non-inoculated control (CK). S1: the germination period; S2: the seedling period; S3: the smoke trailing period; S4: the blooming period 

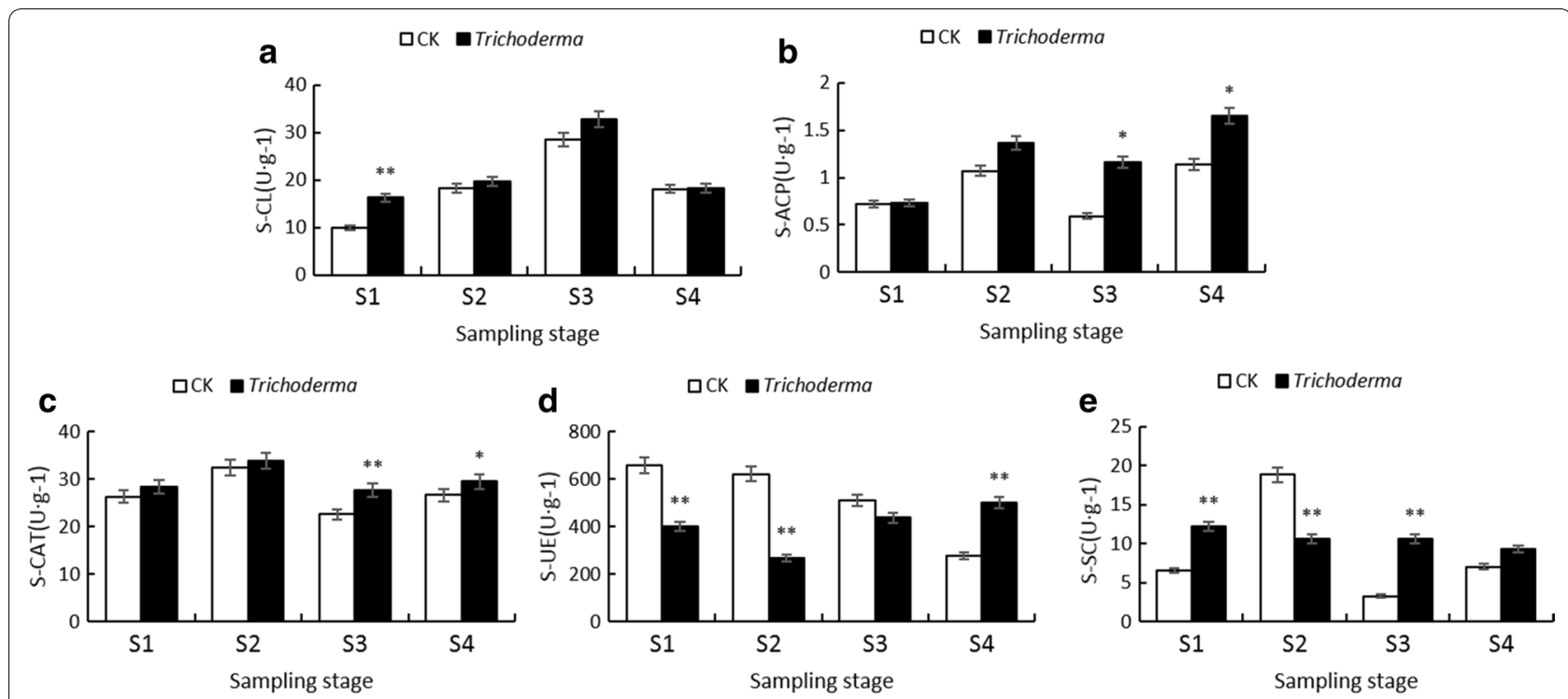

Fig. 2 Effect of inoculating M45a on soil enzyme activities in the rhizosphere of watermelon. The inoculation of T. asperellum M45a in continuous cropping soil (Trichoderma). The non-inoculated control (CK). S1: the germination period; S2: the seedling period; S3: the smoke trailing period; S4: the blooming period

Table 1 Effect of inoculating M45a on soil enzyme activities in the rhizosphere of watermelon

\begin{tabular}{|c|c|c|c|c|c|c|}
\hline Treatment & TC (\%) & $\mathrm{TN}\left(\mathrm{mg} / \mathrm{kg}^{-1}\right)$ & $\mathrm{NH}^{+}\left(\mathrm{mg} / \mathrm{kg}^{-1}\right)$ & $\mathrm{NO3}^{-}\left(\mathrm{mg} / \mathrm{kg}^{-1}\right)$ & $\mathrm{AP}\left(\mathrm{mg} / \mathrm{kg}^{-1}\right)$ & $\mathrm{AK}\left(\mathrm{mg} / \mathrm{kg}^{-1}\right)$ \\
\hline CK 1 & $2.72 \pm 0.09 a$ & $2000.60 \pm 6.86 a$ & $25.24 \pm 0.60 a$ & $364.14 \pm 15.50 \mathrm{a}$ & $67.43 \pm 1.99 a$ & $490.54 \pm 9.46 a$ \\
\hline Trichoderma 1 & $2.65 \pm 0.05 a$ & $2015.34 \pm 3.40 b$ & $24.88 \pm 1.12 \mathrm{a}$ & $367.69 \pm 4.67 a$ & $76.85 \pm 0.77 b$ & $358.29 \pm 6.64 b$ \\
\hline CK 2 & $2.21 \pm 0.09 a$ & $1816.65 \pm 4.10 \mathrm{a}$ & $38.66 \pm 0.51 a$ & $338.55 \pm 11.20 \mathrm{a}$ & $65.44 \pm 1.87 a$ & $511.52 \pm 4.64 a$ \\
\hline Trichoderma 2 & $2.33 \pm 0.12 \mathrm{a}$ & $2058.45 \pm 5.76 b$ & $48.43 \pm 2.01 b$ & $365.94 \pm 6.55 b$ & $68.46 \pm 1.35 a$ & $483.30 \pm 8.31 b$ \\
\hline CK 3 & $2.51 \pm 0.09 a$ & $1807.73 \pm 7.46 a$ & $14.60 \pm 1.13 a$ & $268.75 \pm 8.21 a$ & $69.88 \pm 1.53 a$ & $420.91 \pm 5.63 a$ \\
\hline Trichoderma 3 & $2.27 \pm 0.08 a b$ & $1920.03 \pm 9.10 b$ & $30.38 \pm 1.17 b$ & $283.62 \pm 5.54 a b$ & $63.26 \pm 2.18 b$ & $417.80 \pm 5.93 a$ \\
\hline CK 4 & $2.74 \pm 0.09 a$ & $1797.65 \pm 13.09 a$ & $10.08 \pm 0.80 a$ & $258.40 \pm 10.04 a$ & $56.85 \pm 0.88 a$ & $323.62 \pm 17.40 a$ \\
\hline Trichoderma 4 & $2.58 \pm 0.10 a$ & $1837.18 \pm 6.58 \mathrm{ab}$ & $9.38 \pm 0.78 a$ & $287.23 \pm 8.80 \mathrm{ab}$ & $71.84 \pm 2.21 b$ & $266.37 \pm 6.75 b$ \\
\hline
\end{tabular}

The application of T. asperellum M45a in continuous cropping soil (Trichoderma). The non-inoculated control (CK). Trichoderma1, Trichoderma2, Trichoderma3, Trichoderma4: the treatment with T. asperellum M45a at S1, S2, S3 and S4 period, respectively; CK1, CK2, CK3, CK4: the CK treatments at S1, S2, S3 and S4 period, respectively. S1: the germination period; S2: the seedling period; S3: the smoke trailing period; S4: the blooming period

a Suppression of M45a on FW disease and FON quantity in rhizosphere soil

b Promoting of M45a on watermelon growth and the change of colonization quantity in rhizosphere soil

\section{Effect of T. asperellum M45a on microbial community structure in rhizosphere soil}

In total, 3,607,435 and 3,417,512 high-quality $16 \mathrm{~S}$ and ITS sequences were obtained from the rhizosphere soil samples in the four stages, respectively. In the present study, the significant difference of alpha diversity between the two groups is shown in Fig. 3 and Additional file 1: Table S1. There was a significant difference in Chaol between the group treated with M45a and the CK group (ANOVA, $p<0.05$ ), and the fungal Shannon index values in the M45a group were significantly lower than those of the CK group at all stages (ANOVA, $p<0.01$ ). With the occurrence of watermelon wilt, the fungal Chao1 values in the S1 and S2 groups were significantly higher than those of the S3 and S4 groups (Additional file 1: Table S1, $p<0.05$ ). Additionally, the PCoA results showed that $\mathrm{M} 45 \mathrm{a}(\mathrm{T})$ had a significant effect on the bacterial and fungal community compositions (Fig. 4). The first coordinate (PCoA1) showed differences of $41.1 \%$ and $50.4 \%$ in community variation, and PCoA2 explained $17.6 \%$ and $25.8 \%$ of the dissimilarity, respectively. In addition, these results were further verified by the results of PERANOVA dissimilarity tests based on the 


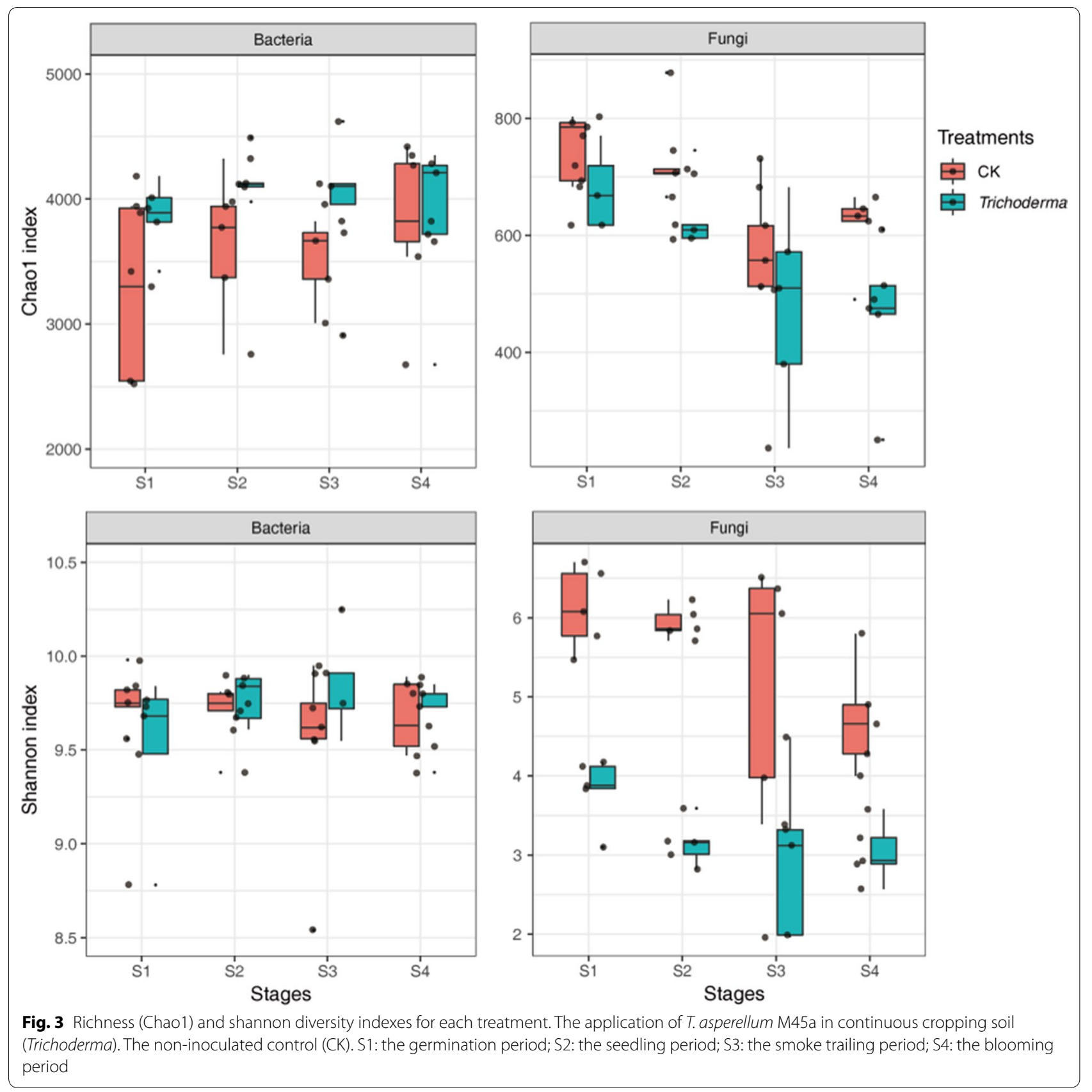

Bray-Curtis distance among the two groups (Bacterial: $\mathrm{R}=0.05787, \mathrm{p}=0.001$; Fungal: $\mathrm{R}=0.27598, \mathrm{p}=0.001$ ).

\section{Effect of T. asperellum M45a on the microbial community composition}

In general, the dominant bacterial phyla between two groups are visualized in the Fig. $5 \mathrm{a}$ and Additional file 2: Fig. S1. In brief, the most abundant bacterial phyla were Proteobacteria, Actinobacteria, Chloroflexi, Gemmatimonadetes, Saccharibacteria, and Acidobacteria, which contributed almost $86.7-91.8 \%$ of the bacterial sequences. While the rhizosphere communities were compared at different growth stages, Saccharibacteria (2.0-14.1\%) was present at a significantly increased proportion in the rhizosphere with the onset of FW. At the genus level, among the top 20 genera, the relative abundance levels of Pseudomonas, Sphingomonas, Actinomadura, and Rhodanobacter in the M45a group were significantly higher than in the CK group (Additional file 2: Fig. S1, $p<0.05)$. 

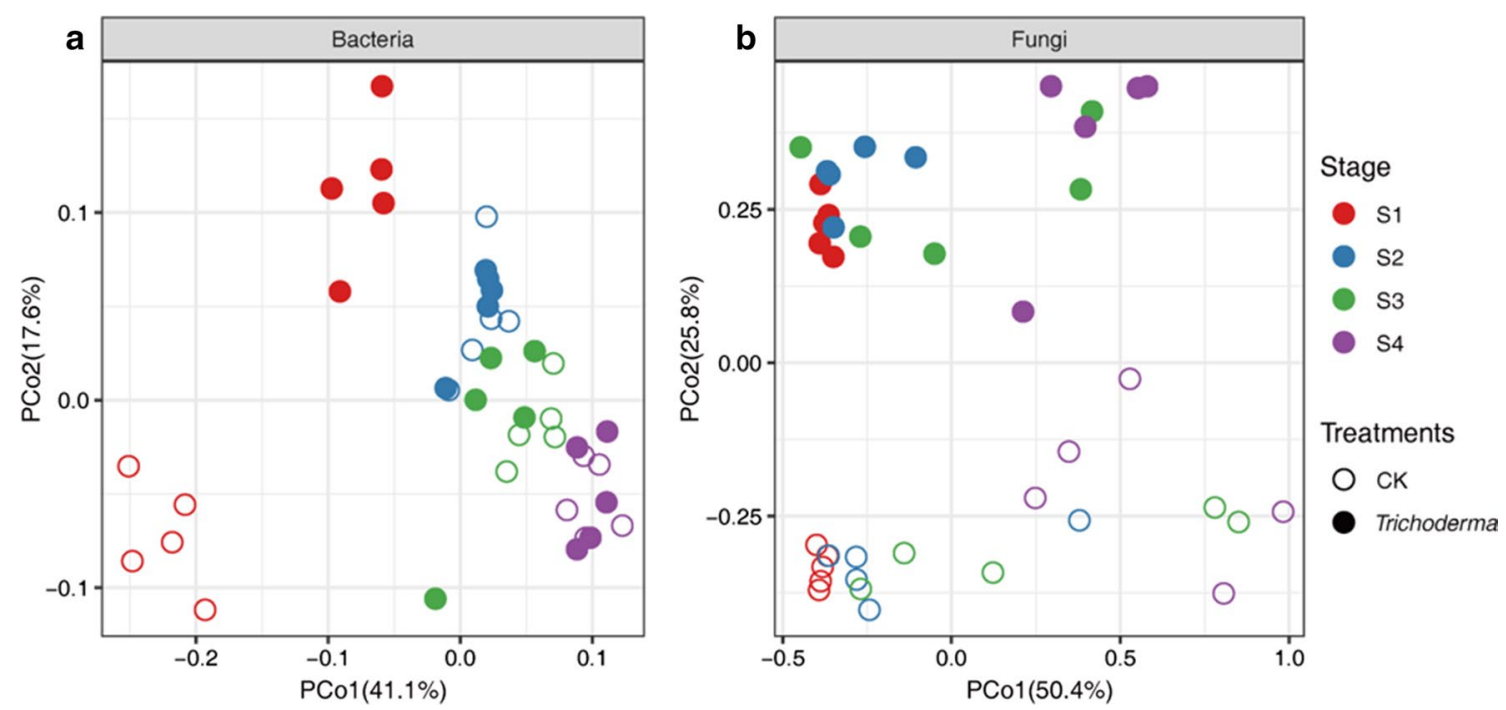

Fig. 4 The PCoA result of the bacterial and fungal communities structure among the different treatment. The application of T. asperellum M45a in continuous cropping soil (Trichoderma). The non-inoculated control (CK). S1: the germination period; S2: the seedling period; S3: the smoke trailing period; 54 : the blooming period
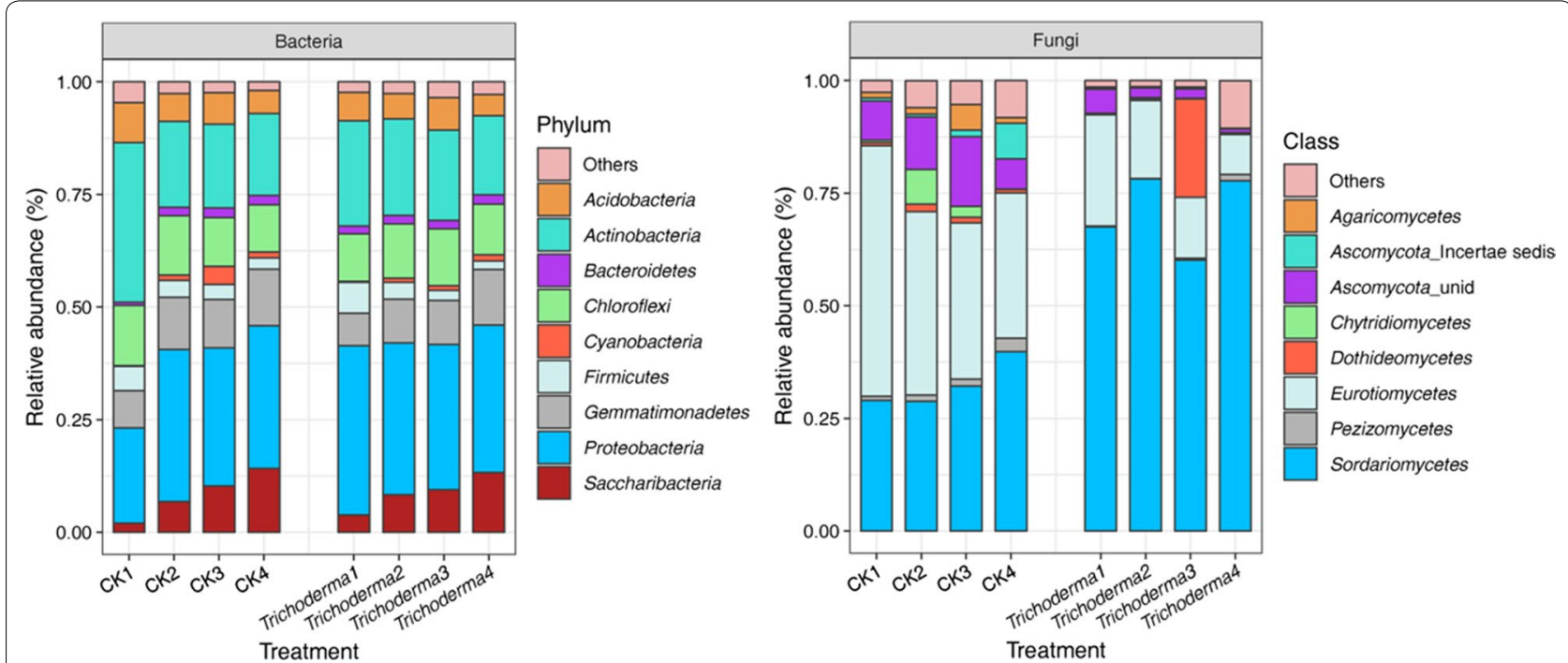

Fig. 5 Relative abundances of bacterial phyla and fungal class under each treatment. The application of T. asperellum M45a in continuous cropping soil (Trichoderma). The non-inoculated control (CK). Trichoderma1, Trichoderma2, Trichoderma3, Trichoderma4: the treatment with T. asperellum M45a at S1, S2, S3 and S4 period, respectively; CK1, CK2, CK3, CK4: the CK treatments at S1, S2, S3 and S4 period, respectively

To investigate the difference in the fungal classes between the two groups, as illustrated in Fig. 5b, we found that the most relative abundant class was Sordariomycetes (60.12-78.67\%) in the M45a group, which was significantly higher than that in the CK group. However, the second relative abundance of Eurotiomycetes was consistently lower in the M45a treatments (0.89-24.71\%) than in the CK group (32.26-55.62\%). For the fungal genera, the relative abundance levels of Penicillium,
Chaetomium, Aspergillus, and Acremonium in the M45a-treated rhizosphere soil were significantly lower than those in the CK group (Fig. S2, $p<0.05$ ). However, Trichoderma was present at a significantly increased proportion during the growth stages in the M45a treatment, consistent with the real-time PCR results. 


\section{Effect of T. asperellum M45a on potential functional} composition diversities

For the bacterial community, amino acid metabolism (10.81-10.98\%), carbohydrate metabolism (10.45$10.81 \%)$, and energy metabolism (5.53-5.81\%) were the main bacterial metabolic pathways in all treatments (Additional file 2: Fig. S3). In this study, the enzyme families (2.02-2.11\%) were different between the M45a treatment and the CK group. Compared with the control soil, functional profiles with lower abundance were related to enzyme families in the M45a-treated soil during different stages, but there were no significant differences in response to disease (Fig. 6a).

For the fungal community, the different functional profiles of the trophic mode (symbiotroph, saprotroph, pathotroph) and guild (plant pathogen) of the fungal communities were compared for the M45a and CK soils during different stages. Compared with the CK soil, the relative abundance levels of ectomycorrhiza, endophytes, animal pathotrophs, and saprotrophs (dung saprotroph, plant saprotroph, soil saprotroph, and wood saprotroph) in the fungal community were significantly lower in M45a-treated soil (Fig. 6b). Additionally, the relative abundance levels of pathogens and other trophic modes showed no significant differences in these treatments.

\section{Relationships among soil enzyme activities, soil properties,} and microbial communities

The RDA analysis showed that enzyme activities (CL, $\mathrm{ACP}$, and CAT) and (AP) could greatly affect the microbial community composition in the rhizosphere soil (Fig. 7). In addition, a significant positive correlation was observed between the DI of FW and the CL activities. However, TN, NH4+-N, and NO3-N were negatively correlated with the DI. Likewise, there were significant positive correlations between Sphingomonas,
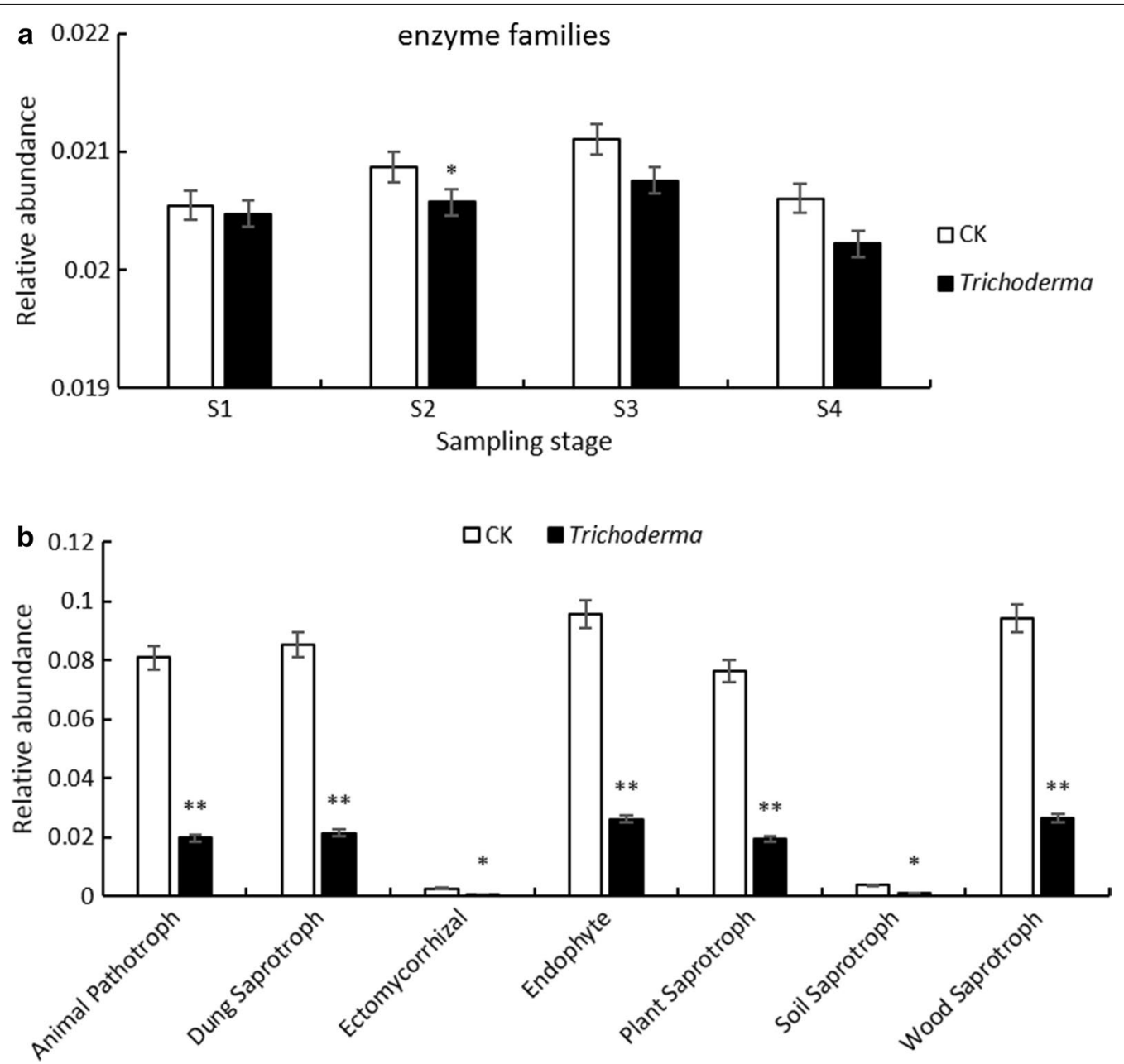

Fig. 6 Relative abundances of bacterial metabolic pathways (a) and fungal trophic modes (b) identified from each treatment. The application of T. asperellum M45a in continuous cropping soil (Trichoderma). The non-inoculated control (CK). S1: the germination period; S2: the seedling period; S3: the smoke trailing period; 54 : the blooming period 

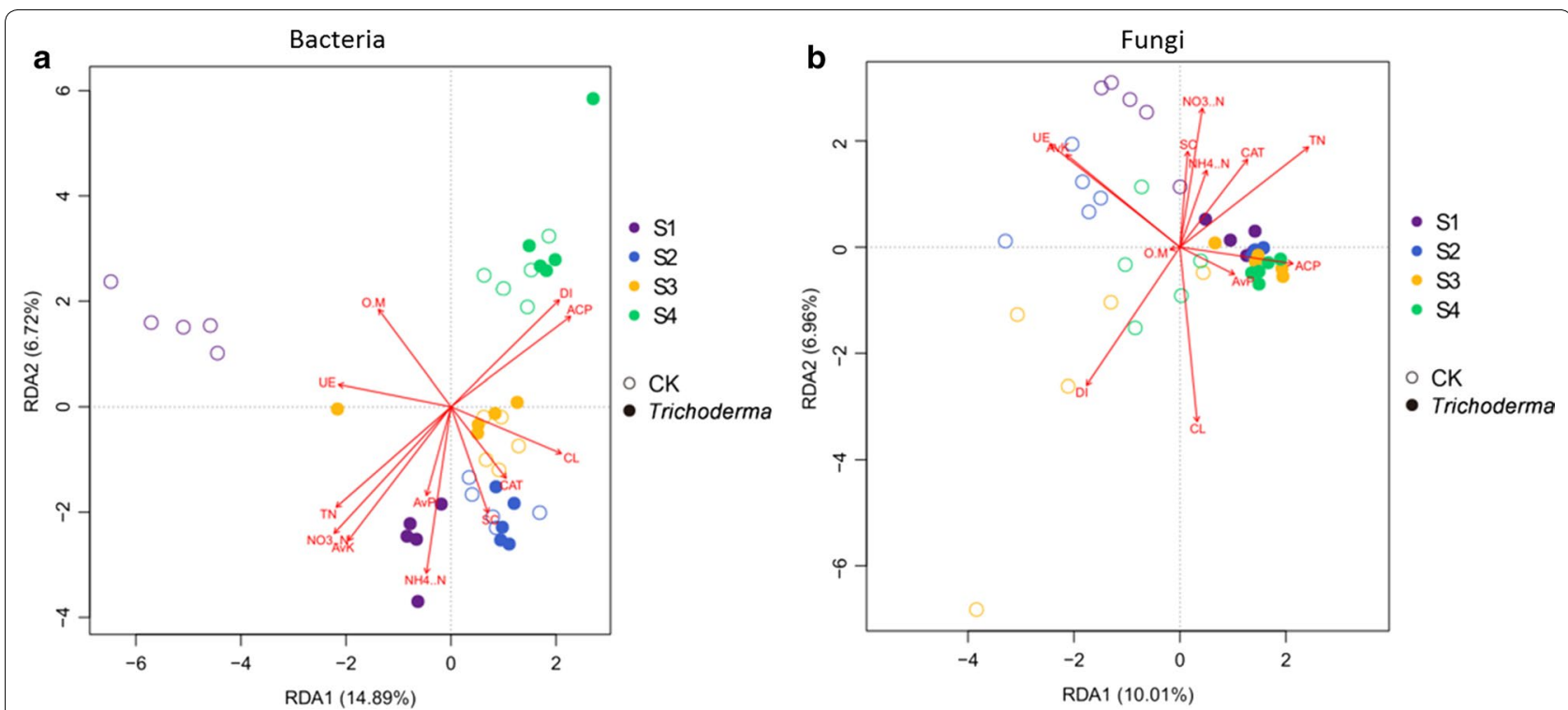

Fig. 7 Redundancy analysis (RDA) of bacterial (a) and fungal (b) genera datasets and measured soil properties in rhizosphere soils after interactive forward selection ( $p<0.05, \mathrm{VIFs}>20$ ). The application of T. asperellum M45a in continuous cropping soil (Trichoderma). The non-inoculated control (CK). S1: the germination period; S2: the seedling period; S3: the smoke trailing period; S4: the blooming period

Rhodanobacter, Pseudomonas, Gemmatimonsa, and Streptomyces and the S-CL activities, and a significant negative correlation was found between Nocardioides and the S-CL activities $(p<0.05)$ (Additional file 1 Table S2). The correlations between the major fungal genera and the rhizosphere soil enzyme activities were then observed (Additional file 1: Table S3). Fungi are likely to be more sensitive to ACP activities than are bacteria; thus, the increased number Trichoderma spp. in the M45a treatment soil was sufficient to impose a stress on the fungi and to thereby influence fungi species such as Penicillium, Chaetomium, Aspergillus, and Dendroclathra, which were significantly negatively correlated with the ACP and SC activities in the rhizosphere soil, while the opposite trend was observed for the UE activities $(p<0.05)$.

\section{Discussion}

Our results show that inoculation with Trichoderma significantly reduced the incidence of watermelon FW and increased the length of watermelon vines under continuous cropping. Many studies have reported that Trichoderma spp. exhibit significant effects against watermelon FW (Wu et al. 2009a, b), tomato late blight (Bahramisharif and Rose, 2018), rice sheath blight (Jambhulkar et al. 2018), maize stalk rot (Li et al. 2016), and banana wilt (Taribuka et al. 2017). Additionally, Trichoderma spp. have significant promoting effects on plants, seedlings and crop yields in some crops, such as those of cucumber, tomato and alfalfa (Zhang et al. 2013a, b; Liu et al. 2017;
Zhang et al. 2019). Trichoderma spp. are adept at promoting plant growth, which is consistent with our result that the length of watermelon vines in the T. asperellum M45a treatment (Trichoderma) was significantly greater than that in the CK treatment. Several studies have demonstrated that Trichoderma spp. can increase the solubilization of soil nutrients (Yedidia et al. 2001; Harman et al. 2004). Trichoderma spp. can produce a large amount of organic acids, which release the delayed nitrogen and available nutrients $(\mathrm{N}, \mathrm{P}$, and $\mathrm{K})$ in the soil for plant growth (Zhang et al. 2019). These findings explain our observation that the M45a treatment had greater contents of available $\mathrm{N}$ and $\mathrm{P}$.

Enzyme activities have been proposed as biological indicators of soil quality and are closely related to soil function (Kandeler et al. 1996; Xian et al. 2015). The activities of CAT, CL, SC, UE, and ACP are closely related to the cycling of SOM, $\mathrm{C}, \mathrm{N}$, and $\mathrm{P}$, respectively (Trasar-cepeda et al. 2007). In our study, M45a significantly increased the activities of CL and ACP, with significant differences observed in the spreading and flowering stages. Compared with the control group, the activities of CL, ACP, CAT, and SC in the soil treated with M45a were all increased, which indicated that T. asperellum M45a could promote the transformation of related enzyme activities such as $\mathrm{N}, \mathrm{C}$, and $\mathrm{P}$ in soil, thus promoting the decomposition of delayed nutrients in soil into available nutrients that can be absorbed and utilized by plants. These findings are consistent with previous studies and indicate that Trichoderma spp. could effectively increase 
the soil enzyme activity and improve plant growth (Zhang et al. 2018; Laur et al. 2018).

The control effect of Trichoderma spp. on watermelon FW was also reflected in the interaction between Trichoderma spp. and FON. After the application of Trichoderma asperellum to the field, the Trichoderma spp. spores can rapidly colonize and reproduce, further inhibiting the reproduction of FON (He et al. 2018). Thus, we further used real-time PCR to quantify the Trichoderma spp. and FON in the rhizosphere soil. The quantitative determination results show that the number of Trichoderma spp. in the rhizosphere soil treated with M45a was 10-fold higher than the control and remained stable during the entire process, while the amount of FON was greater than that in the control treatment only during the smoke trailing period (S3). The most likely reason for this difference is that a large number of FON could cause the occurrence of FW by infecting watermelon roots, while the M45a treatment can induce rapid proliferation of Trichoderma spp. around the rhizosphere of watermelon plants to effectively prevent FON infection in the roots.

As has been previously reported, soil microbial diversity is a key factor affecting soil quality and health (Zhao et al. 2018). Liu et al. (2019) found that continuous cropping led to increases in the diversity and richness of fungi in the rhizosphere soil. Therefore, balancing the rhizosphere soil microecology is crucial for healthy growth. Many studies have demonstrated that low fungal diversity and high bacterial diversity are observed after application of Trichoderma bio-organic fertilizer and Fen-Daqu (Zhang et al. 2016; Zhao et al. 2018). These results are consistent with the findings of our study, which showed that a significant difference was observed in the fungal diversity of the watermelon rhizosphere soil between the M45a and control treatments. The M45a treatment reduced the fungal diversity in the rhizosphere soil. To compare the different populations between the two groups at the genus level, we found that the relative abundance levels of Penicillium, Chaetomium, Aspergillus, and Acremonium in the M45a group were significantly lower than those in the CK group. We hypothesized that $T$. asperellum M45a could rapidly proliferate after inoculation, and reduce the relative abundance levels of Penicillium, Chaetomium, Aspergillus, and Acremonium through nutrient competition, thus regulating the structure and composition of the soil fungal community.

In addition, the soil bacterial and fungal community compositions varied in different treatments, and antagonism may occur between the inoculated Trichoderma and some bacteria (Pan and Jash, 2011). In our study, the abundances of Sphingomonas, Pseudomonas,
Actinomadura, and Rhodanobacter increased significantly in the M45a treatment, which could potentially promote plant growth and health among the top 20 most abundant bacterial genera. Therefore, we hypothesized that the application of M45a may stimulate the proliferation of Pseudomonas, Sphingomonas, and Rhodanobacter, which are widely recognized as beneficial to plant growth and disease resistance (Cordier and Alabouvette, 2009; Laur et al. 2018; Carlson et al. 2019). Functional prediction showed that there was no significant difference in the bacterial metabolic pathways between the two treatments, which is similar to the results described by Benitez et al. (2017). However, fungi such as Chaetomium and Acremonium, which are saprotrophic or pathotrophic fungi that obtain nutrients by attacking host cells, were lacking in the M45a treated soil, so they may exert negative effects on other organisms (Nguyen et al. 2016). Trichoderm (Hu et al. 2016) and Pseudomonas (Wang et al. 2015) have been reported to efficiently control FW, so they may play a synthetic role in promoting plant resistance.

Soil properties have been considered to be an important factor for changing plant rhizosphere microorganisms in previous studies (Zhou et al. 2017). In this study, the RDA results show that M45a inoculation greatly influenced watermelon growth and the DI of FW in the pot experiment and could increase soil available $\mathrm{N}$ and $\mathrm{P}$, which are directly beneficial to plant growth. These findings support our results that the soil available $\mathrm{N}$ and $\mathrm{P}$ contents were significantly higher in the M45a treatment than in the control treatment and that the M45a treatments significantly increased the length of the watermelon vines. The M45a treatment had a negative effect on the soil fungal community, which was most closely associated with changes in soil nutrients and enzyme activities. For example, Trichoderma, Pseudomonas, Sphingomonas, and Rhodanobacter were positively correlated with ACP, CL, CAT, and SC activities, which may indicate that soil enzyme activities are closely associated with living organisms (Govarthanan et al. 2018; Cruz et al. 2018). For species and functional analysis, metagenomic and transcriptomic techniques are required.

Therefore, M45a inoculation regulated the available soil nutrients, rhizosphere soil enzyme activities, and soil microbial community. Additionally, the inoculation indirectly improved crop growth and reduced the DI of FW in the continuously cropped watermelon. These results indicate that improving the plant rhizosphere microbiota can help control soil-borne diseases and promote plant growth. In future studies, we intend to study the microecological mechanisms in different soil environments by exploring the responses of Trichoderma to different soil environments. This will provide valuable information 
regarding the application of Trichoderma in different regions.

\section{Supplementary information}

Supplementary information accompanies this paper at https://doi. org/10.1186/s13568-020-01126-z.

Additional file 1: Figure S1. The dominant bacterial genus differences among two different treatment. The application of T. asperellum M45a in continuous cropping soil (Trichoderma). The non-inoculated control (CK). Trichoderma1, Trichoderma2, Trichoderma3, Trichoderma4: the treatment with T. asperellum M45a at S1, S2, S3 and S4 period, respectively; CK1, CK2, CK3, CK4: the CK treatments at S1, S2, S3 and S4 period, respectively. S1: the germination period; $\mathbf{S 2}$ : the seedling period; $\mathbf{S 3}$ : the smoke trailing period; S4: the blooming period. Figure S2. The dominant fungal genus differences among two different treatment. The application of T. asperellum M45a in continuous cropping soil (Trichoderma). The non-inoculated control (CK). Trichoderma1, Trichoderma2, Trichoderma3, Trichoderma4: the treatment with T. asperellum M45a at S1, S2, S3 and S4 period, respectively; CK1, CK2, CK3, CK4: the CK treatments at S1, S2, S3 and S4 period, respectively. $\mathrm{S} 1$ : the germination period; $\mathrm{S} 2$ : the seedling period; S3: the smoke trailing period; S4: the blooming period. Figure S3. Relative abundances of bacterial metabolic pathways among two different treatment. The application of T. asperellum M45a in continuous cropping soil (Trichoderma). The non-inoculated control (CK).

Additional file 2: Table S1. The dissimilarity test of Richness (Chao1) and shannon diversity indexes for each period. The application of T. asperellum M45a in continuous cropping soil (Trichoderma). The non-inoculated control (CK). Trichoderma1, Trichoderma2, Trichoderma3, Trichoderma4: the treatment with T. asperellum M45a at S1, S2, S3 and S4 period, respectively; CK1, CK2, CK3, CK4: the CK treatments at S1, S2, S3 and S4 period, respectively. S1: the germination period; S2: the seedling period; S3: the smoke trailing period; S4: the blooming period. Table S2. Spearman correlation( $r$ ) coefficients between soil enzyme activities and dominant bacterial populations. * indicates that the significant value $P<0.05,{ }^{* *}$ indicates that the significant value $P<0.01$. ACP: acid phospatase; CAT: catalase; $C L$ : cellulase; UE: urease; SC: sucrase. Table S3. Spearman correlation(r) coefficients between soil enzyme activities and dominant fungal populations. * indicates that the significant value $P<0.05,{ }^{* *}$ indicates that the significant value $P<0.01$. ACP: acid phospatase; CAT: catalase; CL: cellulase; UE: urease; SC: sucrase.

\section{Abbreviations}

FW: Fusarium wilt; DI: Disease incidence; ACP: Acid phospatase; CAT: Catalase; CL: Cellulase; UE: Urease; SC: Sucrase; OM: Organic matter; TN: Total nitrogen; AK: Available kalium; AP: Available phosphorus; PCoA: Principal coordinate analysis; ANOSIM: Analysis of similarities.

\section{Acknowledgements}

The authors are thankful to the Institute of Hunan Agricultural Biotechnology Research for their support in this experiment.

\section{Authors' contributions}

$Z H L$ designed the experiments; $Y Z$ and $Z H L$ performed the experiments; CT and LJX analysed the data; CT prepared figures and/or table; and LW, YT, and $Y Z$ revised this manuscript language. All authors read and approved the final manuscript.

\section{Funding}

This research was supported by funds from the National Key Research and Development Program of China (2017YFD0200606 and 2018YFD0201300) and the Hunan Natural Science Foundation (2019JJ40160).

\section{Availability of data and materials}

The strains are available upon request. All data obtained have been included in the manuscript and the additional files.
Ethics approval and participant consent

Not applicable.

\section{Consent for publication}

Not applicable.

\section{Competing interests}

The authors declare that they have no competing interests.

\section{Author details}

${ }^{1}$ College of Bioscience and Biotechnology, Hunan Agricultural University, Changsha, Hunan, China. ${ }^{2}$ Institute of Agricultural Biotechnology Research, Hunan Academy of Agricultural Sciences, Changsha, Hunan, China. ${ }^{3}$ Institute of Plant Protection, Hunan Academy of Agricultural Sciences, Changsha, Hunan, China.

Received: 18 June 2020 Accepted: 15 October 2020

Published online: 23 October 2020

\section{References}

Allison SD, Jastrow JD (2006) Activities of extracellular enzymes in physically isolated fractions of restored grassland soils. Soil Biol Biochem 38:3245-3256. https://doi.org/10.1016/j.soilbio.2006.04.011

An MJ, Zhou XG, Wu FZ, Ma YF, Yang P (2011) Rhizosphere soil microorganism populations and community structures of different watermelon cultivars with differing resistance to Fusarium oxysporum f. sp. niveum. Can J Microbiol 57:355-365. https://doi.org/10.1139/w11-015

Bahramisharif A, Rose LE (2018) Efficacy of biological agents and compost on growth and resistance of tomatoes to late blight. Planta 249:799-813. https://doi.org/10.1007/s00425-018-3035-2

Benitez MS, Osborne SL, Lehman RM (2017) Previous crop and rotation history effects on maize seedling health and associated rhizosphere microbiome. Sci Rep 7:1-13. https://doi.org/10.1038/s41598-017-15955-9

Caporaso JG, Kuczynski J, Stombaugh J, Bittinger K, Bushman FD, Costello EK, Fierer N, Pena AG, Goodrich JK, Gordon JI, Huttley GA, Kelley ST, Knights D, Koenig JE, Ley RE, Lozupone CA, McDonald D, Muegge BD, Pirrung M, Reeder JR, Sevinsky JR, Turnbaugh PJ, Walters WA, Widmann J, Yatsunenko T, Zaneveld J, Knight R (2010) QIIME allows analysis of high-throughput community sequencing data. Nat Methods 7:335-336. https://doi. org/10.1038/nmeth.f.303

Carlson H, Price M, Callaghan M, Aaring A, Chakraborty R, Liu H, Kuehl JV, Arkin AP, Deutschbauer AM (2019) The selective pressures on the microbial community in a metal-contaminated aquifer. ISME J 13:937-949. https:// doi.org/10.1038/s41396-018-0328-1

Cordier C, Alabouvette C (2009) Effects of the introduction of a biocontrol strain of trichoderma atroviride on non target soil micro-organisms. Eur J Soil Biol 45:267-274. https://doi.org/10.1016/j.ejsobi.2008.12.004

Cruz AF, Barka GD, Sylla J, Reineke A (2018) Biocontrol of strawberry fruit infected by Botrytis cinerea: Effects on the microbial communities on fruit assessed by next-generation sequencing. J Phytopathol 166:403-411. https://doi.org/10.1111/jph.12700

Desantis TZ, Hugenholtz P, Larsen N, Rojas M, Brodie EL, Keller K, Huber T, Dalevi D, Hu P, Andersen GL (2006) Greengenes, a chimera-checked $16 \mathrm{~S}$ rrna gene database and workbench compatible with ARB. Appl Environ Microbiol 72:5069-5072. https://doi.org/10.1128/AEM.03006-05

Edgar RC (2010) Search and clustering orders of magnitude faster than BLAST. Bioinformatics 26:2460-2461

Emami S, Pourbabaee AA, Alikhani HA (2013) Effect of paraffin on the urease activity of soil. Tech J Eng Appl Sci 3:1526-1529

Faheem M, Raza W, Wei Z, Zhang N, Shen QR, Xu YC (2015) Evaluation of the biocontrol potential of Streptomyces goshikiensis YCXU against Fusarium oxysporum f. sp. niveum. Biol Control 81:101-110. https://doi. org/10.1016/j.biocontrol.2014.11.012

Fang SZ, Liu D, Tian Y, Deng SP, Shang XL (2013) Tree species composition influences enzyme activities and microbial biomass in the rhizosphere: a rhizobox approach. PLoS ONE 8:e61461. https://doi.org/10.1371/journ al.pone.0061461

Gao ZY, Han MK, Hu YY, Li ZQ, Liu CF, Wang X, Tian Q, Jiao WJ, Hu JM, Liu LF, Guan ZJ, Ma ZM (2019) Effects of countinuous cropping of sweet potato 
on the fungal community structure in rhizospheric soil. Front Microbiol 10:1-11. https://doi.org/10.3389/fmicb.2019.02269

García-Ruiz R, Ochoa V, Hinojosa MB, Carreira JA (2008) Suitability of enzyme activities for the monitoring of soil quality improvement in organic agricultural systems. Soil Biol Biochem 40:2137-2145. https://doi. org/10.1016/j.soilbio.2008.03.023

Guo SG, Zhang JG, Sun HH, Salse J, Lucas WJ, Zhang HY, Zheng Y, Mao LY, Ren Y, Wang ZW, Min M, Guo XS, Murat F, Ham BK, Zhang ZL, Gao S, Huang MY, Xu YM, Zhong SL, Bombarely A, Mueller LA, Zhao H, He HJ, Zhang Y, Zhang ZH, Huang SW, Tan T, Pang E, Lin K, Hu Q, Kuang HH, Ni PX, Wang B, Liu JA, Kou QH, Hou WJ, Zou XH, Jiang J, Gong GY, Klee K, Schoof H, Huang Y, Hu XS, Dong SS, Liang DQ, Wang J, Wu K, Xia Y, Zhao X, Zheng $Z Q$, Xing $M$, Liang $X X$, Huang $B Q$, Lv T, Wang JY, Yin Y, Yi HP, Li RQ, Wu MZ, Levi A, Zhang XP, Giovannoni JJ, Wang J, Li YF, Fei ZJ, Xu Y (2013) The draft genome of watermelon (Citrullus lanatus) and resequencing of 20 diverse accessions. Nat Genet 45:51-58. https://doi.org/10.1038/s4158 8-019-0518-4

Govarthanan M, Mythili R, Selvankumar T, Kamala-Kannan S, Kim H (2018) Myco-phytoremediation of arsenic- and lead-contaminated soils by Helianthus annuus and wood rot fungi, Trichoderma sp isolated from decayed wood. Ecotox Environ Safe 151:279-284. https://doi.org/10.1016/j,ecoen v.2018.01.020

Harman GE, Howell CR, Viterbo A, Chet I, Lorito M (2004) Trichoderma species opportunistic, avirulent plant symbionts. Nat Rev Microbiol 2:43-56. https ://doi.org/10.1038/nrmicro797

He AL, Liu J, Wang XH, Zhang QG, Wei S, Chen J (2019) Soil application of Trichoderma asperellum GDFS1009 granules promotes growth and resistance to fusarium graminearum in maize. J Integr Agric 18:599-606. https ://doi.org/10.1016/S2095-3119(18)62089-1

He ZD, Wu CC, Shen JJ, Gao YF, Chang LS, Gao ZG (2018) Effects of Trichoderma asperellum biofertilizer on cucumber Fusarium wilt and microbial population in continuous cucumber cropping rhizosphere soil. J Plant Protect 45:528-535. https://doi.org/10.13802/j.cnki.zwbhx b.2018.2016195

Hermosa R, Viterbo A, Chet I, Monte E (2012) Plant-beneficial effects of Trichoderma and of its genes. Microbiology 158:17-25. https://doi.org/10.1099/ mic.0.052274-0

Hu XJ, Roberts DP, Xie LH, Yu CB, Li YS, Qin L, Hu L, Zhang YB, Liao X (2016) Use of formulated Trichoderma sp Tri-1 in combination with reduced rates of chemical pesticide for control of Sclerotinia sclerotiorium on oilseed rape. Crop Prot 79:124-127. https://doi.org/10.1016/j.cropro.2015.10.020

Jambhulkar PP, Sharma P, Manokaran R, Lakshman DK, Rokadia P, Jambhulkkar N (2018) Assessing synergism of combined applications of trichoderma harzianum and pseudomonas fluorescens to control blast and bacterial leaf blight of rice. Eur J Plant Patho 152:747-757. https://doi.org/10.1007/ s10658-018-1519-3

Jiang XT, Peng X, Deng GH, Sheng HF, Wang Y, Zhou HW, Tam NFY (2013) Illumina Sequencing of $16 \mathrm{~S}$ rRNA Tag Revealed Spatial Variations of Bacterial Communities in a Mangrove Wetland. Microb Ecol 66:96-104. https://doi. org/10.1007/s00248-013-0238-8

Jongman RHJ, Braak CJF, Tongeren OFR (1995) Data analysis in community and landscape ecology: List of Contributors. Cambridge University, Cambridge, pp 91-173

Kandeler F, Kampichler C, Horak O (1996) Influence of heavy metals on the functional diversity of soil microbial communities. Biol Fertil Soils 23:299-306. https://doi.org/10.1007/bf00335958

Kizilkaya R, Akca I, Askin T, Yilmaz R, Olekhov V, Samofalova L, Mudrykh N (2012) Effect of soil contamination with azadirachtin on dehydrogenase and catalase activity of soil. Eur J Soil Sci 24:98-103

Laur J, Ramakrishnan GB, Labbe C, Lefebvre F, Spanu PD, Belanger RR (2018) Effectors involved in fungal-fungal interaction lead to a rare phenomenon of hyperbiotrophy in the tritrophic system biocontrol agent-powdery mildew-plant. New Phytol 217:713-725. https://doi.org/10.1111/ nph. 14851

Li YQ, Sun RY, Yu J, Saravanakumar K, Chen J (2016) Antagonistic and biocontrol potential of trichoderma asperellum zjs×5003 against the maize stalk rot pathogen fusarium graminearum. Indian J Microbiol 56:318-327. https ://doi.org/10.1007/s12088-016-0581-9

Li Y, Zhang LP, Fang SZ, Tian Y, Gou J (2018) Variation of soil enzyme activity and microbial biomass in poplar plantations of different genotypes and stem spacings. J For Res 4:1-10. https://doi.org/10.1007/s1167 6-017-0524-2

Liu H, Pan FJ, Han XZ, Song FB, Zhang ZM, Yan J, Xu YL (2019) Response of soil fungal community structure to long-term continuous soybean cropping. Front Microbiol 9:1-9. https://doi.org/10.3389/fmicb.2018.03316

Liu QM, Chen X, Meng XH, Ye Q, Li T, Liu DY, Shen QR (2017) Development of a new type of biological organic fertilizer and its effect on the growth promotion of tomato. Chin J Appl Ecol 28:3314-3322. https://doi. org/10.13287/j.1001-9332.201710.039

Lopez-Mondejar R, Anton A, Raidl S, Ros M, Pascual JA (2010) Quantification of the biocontrol agent Trichoderma harzianum with real-time TaqMan PCR and its potential extrapolation to the hyphal biomass. Bioresour Technol 101:2888-2891. https://doi.org/10.1016/j.biortech.2009.10.019

Mazzola M (2004) Assessment and management of soil microbial community structure for disease suppression. Ann Rev Phytopathol 42:35-59. https:// doi.org/10.1146/annurev.phyto.42.040803.140408

Nguyen NH, Song Z, Bates ST, Branco S, Tedersoo L, Menke J, Schilling JS, Kennedy PG (2016) FUNGuild: An open annotation tool for parsing fungal community datasets by ecological guild. Fungal Ecol 1:241-248. https:// doi.org/10.1016/j.funeco.2015.06.006

Pan S, Jash S (2011) Variability in biocontrol potential and microbial interaction of Trichoderma spp. with soil inhabiting antagonistic bacteria Pseudomonas fluorescens. Indian Phytopathol 2:158-164

Pandey V, Ansari MW, Tula S, Yadav S, Sahoo RK, Shukla N, Bains G, Badal S, Chandra S, Gaur AK, Kumar A, Shukla A, Kumar J, Tuteja N (2016) Dosedependent response of Trichoderma asperellum in improving drought tolerance in rice genotypes. Planta 243:1251-1264. https://doi.org/10.1007/ s00425-016-2482-X

Philippot L, Raaijmakers JM, Lemanceau P, Putten WV (2013) Going back to the roots: the microbial ecology of the rhizosphere. Nat Rev Microbiol 11:789-799. https://doi.org/10.1038/nrmicro3109

Raaijmakers JM, Paulitz TC, Steinberg C, Alabouvette C, Moenne-Loccoz Y (2009) The rhizosphere: a playground and battlefield for soilborne pathogens and beneficial microorganisms. Plant Soil 321:341-361. https://doi. org/10.1007/s11104-008-9568-6

Shen ZZ, Ruan YZ, Chao X, Zhang J, Li R, Shen QR (2015) Rhizosphere microbial community manipulated by 2 years of consecutive bio-fertilizer application associated with banana Fusarium wilt disease suppression. Biol Fertil Soils 51:553-562. https://doi.org/10.1007/s00374-015-1002-7

Shen ZZ, Ruan YZ, Wang BB, Zhong ST, Su LX, Li R, Shen QR (2015) Effect of biofertilizer for suppressing Fusarium wilt disease of banana as well as enhancing microbial and chemical properties of soil under greenhouse trial. Appl Soil Ecol 93:111-119. https://doi.org/10.1016/j.apsoi I.2015.04.013

Taribuka J, Wibowo A, Widyastuti SM, Sumardiyono C (2017) Potency of six isolates of biocontrol agents endophytic Trichoderma against fusarium wilt on banana. J Degrad Mining Lands Manag 34:723-731. https://doi. org/10.15243/jdmlm.2017.042.723

Trasar-Cepeda C, Gil-Sotres F, Leios MC (2007) Thermodynamic parameters of enzymes in grassland soils from Galicia, NW Spain. Soil Biol Biochem 39:311-319. https://doi.org/10.1016/j.soilbio.2006.08.002

Umadevi P, Anandaraj M, Srivastav V, Benjamin S (2018) Trichoderma harzianum mtcc 5179 impacts the population and functional dynamics of microbial community in the rhizosphere of black pepper (piper nigrum L.). Braz J Microbiol 49:463-470. https://doi.org/10.1016/j.bjm.2017.05.011

Urmas K, Nilsson RH, Abarenkov K, Tedersoo L, Taylor AFS, Bahram M, Bates ST, Bruns TD, Bengtsson-Palme J, Callaghan TM, Douglas B, Drenkhan T, Eberhardt U, Duenas M, Grebenc T, Griffith GW, Hartmann M, Kirk PM, Kohout P, Larsson E, Lindahl BD, Lucking R, Martin MP, Matheny PM, Nguyen NH, Niskanen T, Oja J, Peay KG, Peintner U, Peterson M, Paldmaa K, Saag L, Saar I, Schuller A, Scott JA, Senes C, Simth ME, Suija A, Taylor DE, Telleria MT, Weiss M, Larsson KH (2013) Towards a unified paradigm for sequence-based identification of fungi. Mol Ecol 22:5271-5277. https:// doi.org/10.1111/mec.12481

Wang K, Yin XB, Mao HL, Chu C, Tian Y (2018) Changes in structure and function of fungal community in cow manure composting. Bioresour Technol 255:123-130. https://doi.org/10.1016/j.biortech.2018.01.064

Wang XF, Mavrodi DV, Ke LF, Mavrodi OV, Yang MM, Thomashow LS, Zheng N, Weller DM, Zhang JB (2015) Biocontrol and plant growthpromoting activity of rhizobacteria from Chinese fields with 
contaminated soils. Microb Biotechnol 8(665):404-418. https://doi. org/10.1111/1751-7915.12158

Wei W, Zhu YL, Zhu L, Dong N, Han XZ, Li S (2013) Establishment and application of a real-time quantitative PCR assay for the detection of soil Trichoderma spp. Soil Crop 1:53-58. https://doi.org/10.11689/j.i ssn.2095-2961.2013.01.009

Wu HS, Yang XN, Fan JQ, Miao WG, Ling N, Xu YC, Huang QW, Shen QR (2009) Suppression of Fusarium wilt of watermelon by a bio-organic fertilizer containing combinations of antagonistic microorganisms. Biol Control 54:287-300. https://doi.org/10.1007/s10526-008-9168-7

Wu FZ, Wang XZ, Xue CY (2009) Effect of cinnamic acid on soil microbial characteristics in the cucumber rhizosphere. Eur J Soil Biol 45:356-362. https ://doi.org/10.1016/j.ejsobi.2009.04.001

Xiao JL, Zhang Y, Li JG, Zhu FY, Wei L, Liang ZH (2018) Establishment of realtime PCR system for quantitatively detecting Fusarium oxysporum $\mathrm{f}$. sp. niveum in soil. J Plant Protect 45:921-922. https://doi.org/10.13802/j.cnki. zwbhxb.2018.2017032

Xian Y, Wang ME, Chen WP (2015) Quantitative assessment on soil enzyme activities of heavy metal contaminated soils with various soil properties. Chemosphere 139:604-608. https://doi.org/10.1016/j.chemospher e.2014.12.060

Yang XM, Chen LH, Yong XY, Shen QR (2011) Formulations can affect rhizosphere colonization and biocontrol efficiency of Trichoderma harzianum SQR-T037 against Fusarium wilt of cucumbers. Biol Fertil Soils 47:239-248. https://doi.org/10.1007/s00374-010-0527-z

Yedidia I, Srivastva AK, Kapulnik Y, Chet I (2001) Effect of Trichoderma harzianum on microelement concentrations and increased growth of cucumber plants. Plant Soil 235:235-242. https://doi.org/10.1023/a:10119 90013955

Yu L, Nicolaisen M, Larsen J, Ravnskov S (2013) Organic fertilization alters the community composition of root associated fungi in Pisum sativum. Soil Biol Biochem 58:36-41. https://doi.org/10.1016/j.soilbio.2012.11.004

Yuan Y, Wang YC, Zeng B, Zhang JH, Han YZ (2018) Effect of five Trichoderma strains on growth and nutritional quality of Orchard grass. Pratacult Sci 35:391-397

Zhang FG, Zhu Z, Yang XM, Ran W, Shen QR (2013) Trichoderma harzianum T-E5 significantly affects cucumber root exudates and fungal community in the cucumber rhizosphere. Appl Soil Ecol 72:41-48. https://doi. org/10.1016/j.apsoil.2013.05.016
Zhang FG, Yuan J, Yang XM, Cui YQ, Chen LH, Ran W, Shen QR (2013) Putative Trichoderma harzianum mutant promotes cucumber growth by enhanced production of indole acetic acid and plant colonization. Plant Soil 368:433-444. https://doi.org/10.1007/s11104-012-1519-6

Zhang FG, Xu XX, Huo YQ, Xiao Y (2019) Trichoderma-inoculation and mowing synergistically altered soil available nutrients, rhizosphere chemical compounds and soil microbial community, potentially driving alfalfa growth. Front Microbiol 9:1-12. https://doi.org/10.3389/fmicb.2018.03241

Zhang HX, Zeng XB, Bai LY, Shan H, Wang YN, Wu CX, Duan R, Su SM (2018) Reduced arsenic availability and plant uptake and improved soil microbial diversity through combined addition of ferrihydrite and Trichoderma asperellum SM-12F1. Environ Sci Pollut Res 25:24125-24134. https://doi. org/10.1007/s11356-018-2451-y

Zhang HX, Zhang XH, Zhao JL, Du XW, Ma B (2016) Analysis of the microbial communities of three kinds of Fen-Daqu by PLFAs. J Inst Brew 122:34-41. https://doi.org/10.1002/jib.292

Zhang ZG, Zhang JY, Wang YC, Wang YC (2005) Molecular detection of Fusarium oxysporum f. sp. niveum and Mycosphaerella melonis in infected plant tissues and soil. FEMS Microbiol Lett 249:39-47. https://doi.org/10.1016/j. femsle.2005.05.057

Zhao J, Liu J, Liang H, Huang J, Chen Z, Nie YJ, Wang CB, Wang YG (2018) Manipulation of the rhizosphere microbial community through application of a new bio-organic fertilizer improves watermelon quality and health. PLoS ONE 13:e192967. https://doi.org/10.1371/journ al.pone.0192967

Zhao S, Liu DY, Ling N, Chen FD, Fang WM, Shen QR (2014) Bio-organic fertilizer application significantly reduces the Fusarium oxysporum population and alters the composition of fungi communities of watermelon Fusarium wilt rhizosphere soil. Biol Fertil Soils 50:765-774. https://doi.org/10.1007/ s00374-014-0898-7

Zhou XG, Liu J, Wu FZ (2017) Soil microbial communities in cucumber monoculture and rotation systems and their feedback effects on cucumber seedling growth. Plant Soil 415:507-520. https://doi.org/10.1007/s 1110 4-017-3181-5

\section{Publisher's Note}

Springer Nature remains neutral with regard to jurisdictional claims in published maps and institutional affiliations.

\section{Submit your manuscript to a SpringerOpen ${ }^{\circ}$ journal and benefit from:}

- Convenient online submission

- Rigorous peer review

- Open access: articles freely available online

- High visibility within the field

Retaining the copyright to your article

Submit your next manuscript at $\boldsymbol{\nabla}$ springeropen.com 